\title{
Research into the Professionalization of China's Sports Brokers
}

\author{
Huang Zhaoyuan \\ ( Institute of Physical Education, Changchun Normal University, \\ Changchun Jilin Province, China ) \\ e-mail: hzy1353160@sina.com
}

\begin{abstract}
In this paper, the development of and the problems in China's sports brokers are analyzed and studied. According to the results, there are some problems in the development of the sports brokers in China: the sports market system is not well developed, the information about the sports broker market is not well communicated, and the operation level of sports broker is very low, etc. The professionalization of Chinese sports brokers is the drive to the scientific development of the Chinese sports broker industry.
\end{abstract}

Keywords-sports broker;development status; sportsmen; brokerage; professionalization

\section{INTRODUCTION}

Sports brokers originate from the west, and have less than one hundred years' history. Seen from its formation background, it is a transitional product from amateur sports to professional sports. At the end of the 19th, baseball took the lead to commence its professionalization, and then American football and basketball also started to be professionalized[1]. In 1925, a drama seller C.C.Paarai entered into an agency contact with Halas-George and became the first sports broker in USA. In 1997[2], the famous high jumper Zhu Jianhua registered "Hope International Sports Brokerage Co., Ltd" in Shanghai and this company was the first professional sports agency in China.

In 2008, Beijing Olympics was successfully held, and China's sports keep developing, in particular the socialization and the industrialization of sports urgently need sports brokers like those famous ones in suits overseas who work with clubs in Europe and USA, and may earn a lot on successful deals[3]. However, there is a great gap between the sports brokers in China and those in USA and Europe, so our brokers need not only to learn the knowledge and practice skills on how to be a good broker, but also to learn and study the development and the direction of the sports market, the market needs higher quality of persons engaged in the industry, and professionalization of sports brokers has become a necessary tendency.

\section{THE DEVELOPMENT STATUS AND PROBLEMS OF THE}

\section{SPORTS BROKERS IN CHINA}

Generally speaking, the sports brokers in China are classified into three types: competition brokers, sportsman brokers and sports organization brokers and the first type accounts for the majority part. It is inevitable for the sports in China to be market-oriented. So there are a lot of treasures for us to dig in the sports industry of China, and the sports market is very broad to develop with a lot of various categories involved, such as introduction of sportsmen, transfer between clubs, various competitions held, training of talents by various sports schools, tickets, sports lottery, advertisement, souvenirs for fans, and development and operation of various sports goods and so on[4]. The development of these sports industries need a lot of operation and management professionals and brokers in China. However, seen from the development of China's sports brokerage industry, China's sports brokerage industry is still very young compared with those overseas. As the commercialization of China's sports industry starts late, and is bound by traditional planned economy system, there are a lot of problems in the development of the sports brokers.

\section{A. Underdeveloped sports market system}

As China's sports market is still in the early stage, the system is still unsound, and the sports elements are not liberalized yet, and sports brokers are restricted. The sports associations play three parts, namely, government's roles, development of the sports industry and management as associations. The associations' responsibilities for management, handling and operation exist simultaneously and will last for a considerable time[5]. The unfair competitions arising from monopoly in the industry and of projects inhibit the sports brokers from playing an active role and their functions' efficiency.

\section{B. Sports broker market information not communicated smoothly}

The big gaps in regions, timing, professionalism, interpersonal relationships bring great values to the sports brokers, and in order to achieve the values, sports brokers need to grasp a lot of information concerned, however, there are no authoritative information platforms in China, and it is difficult to improve the market values of the sports brokers and their activities without smooth communication of sports market information.

\section{Low level of operation of China's sports brokers}

Sports brokerage activities, as the intermediary and bridge of the sports market, often involve various disciplines, such as sports, economy, advertisement, marketing, public relations and others[6]. The persons practicing in this industry must meet certain requirements, be highly qualified and have broad knowledge and comprehensive abilities. Their comprehensive quality 
directly affects the development of the whole sports industry. However, in general, China's sports brokers are of low quality. As the sports market starts to develop late, and employees in this industry are trained just for very short term before they take their jobs, and long-term development of professionals has not produced outstanding results yet, and very few people help to drive the market to develop. Accordingly, there are few excellent persons in the sports broker market. Most of the sports brokers deal with sports brokerage as one of their businesses, so they tend to have no expertise and in particular in foreign brokerage activities, some are even cheated as they have no experience and are not well conscious of protecting themselves.

\section{NECESSITY OF THE PROFESSIONALIZATION OF CHINA'S SPORTS BROKERS}

Brokerage of sportsmen is a very professional economic activity. As the Chinese proverb says, difference in profession makes one feel worlds apart. Those who intend to undertake brokerage tasks must have not only knowledge about general economic activities, but also abundant knowledge about sports. However, as the society develops, the work is divided more and more definitely, and professionalization of sports brokers is inevitable. However, under such a circumstance, it is necessary to attach great importance to the sports brokers and call them into play due to their professional characteristics and expertise. However, time and environment are needed in order to professionalize sports brokers and professionalization of sports brokers is inevitable.

\section{A. Professional sports brokers needed for sportsmen's transfer economy}

Scientific arrangement of and participation in competitions are important for improving sportsmen's skills of having sports. For high-level athletes, competition is an indispensible constituent[7]. One important principle for acting as agents of sportsmen to participate in competitions is to improve and keep their skills and athletic ability. The ideal economic result is that the sportsmen not only get greater economic benefits from the competitions, but also improve and keep their athletic skills and abilities. For this purpose, sportsmen's competition brokers shall know the competitions very well, and discuss and work out the sportsmen's competition arrangement with the sportsmen they act for, their clubs, national sportsmen associations to choose competitions for the sportsmen to participate in. The sportsmen shall be arranged to participate in the competitions having greater economic benefits and better business opportunities while considering their overall training schedules.

\section{B. Professional sports brokers needed for the sportsmen to participate in competitions}

Professionalized brokers must know well and observe the rules and regulations of international sports organizations and national sports associations, are able to help sportsmen to observe the rules of international sports organizations and national sports associations concerning qualifications for participation in competitions, have thorough knowledge of competition information, and discuss and work out the sportsmen's competition arrangements with sportsmen, coaches, clubs and national sports associations, and ensure that the sportsmen they act for participate in the competitions organized by the international sports organizations and international sports association. Once they have entered into competition contracts, they shall make every effort to ensure that the sportsmen will fulfill the contracts.

\section{Professional sports brokers needed for commercial development of sportsmen}

1) Control and protection of sportsmen's portrait right : At present, many European football clubs purchase sportsmen's portrait rights directly from their brokers so that the portrait rights become one part of the entire contract. Let us take the football players from Real Madrid for example. Except for the contracts that have not been completely fulfilled previously, the football players must submit their portrait rights to the clubs and the portrait rights are also a source for them to earn money. Butrague, CEO of the club, said that as a condition of joining the club, the sportsmen must agree that the club would manage their portrait right, which was a club principle that must be accepted by them, and their business activities must be arranged by us and we would divide the income with the football players[8]. What the brokers do in this course is just negation. Professional brokers must pay attention to protect the sportsmen's portrait rights from being infringed, and urge the sportsmen to protect their own reputations.

2) Know how to deal with sponsors:

Sportsmen's endorsement for enterprises is increasingly popular. Such famous sports stars as Yao Ming and Liu Xiang have endorsed for a lot of brands, and sports brokers shall choose proper sponsors for the sportsmen based on their images, in particular, in terms of negotiation with sponsors, the sports brokers shall try their best to be clear about the real strength of the enterprises, and try for the maximum benefits and guarantee for the sportsmen and the brokers[9]. Before Beijing Olympics, Yao Ming had entered into dozens of advertisement contracts, including those with China Unicom, Sohu, Apple Computer, Gatorade, McDonald's, Reebok, Pepsi, and mobile games of Solent and has earned dozens of millions of dollars on advertisement[10]. Team Yao consisting of Zhang Mingji, leader of the broker team, Lu Hao, a Chinese broker and others, is highly reputed for their professional operation model and abilities in the sports industry.

\section{3) Maximization of sportsmen's values :}

Insightful sports brokers tend to enter into brokerage contracts with sportsmen before they become famous, and market them when appropriate, and have got the maximum values from market development. McCormack is the founder of packaging famous sports stars and the broker concept, and he took the lead to introduce the concept of "package" into the sports industry, and his talent is reflected in his proposal of the concept of creating sportsmen as superstars, and imparting persons with a new concept that football players also need creating. 


\section{CONCLUSIONS}

In recent years, sports brokers have become an indispensible intermediary due to the high demands of the sports market, and the career of sports brokers is emerging silently in China, and basic conditions have formed for sports brokers to become a social career. Stimulated by the demand of the sports market, sports brokers will surely become favorite market players in China's sports industry. We must see that China's sports brokerage career has not started to develop healthily yet, and there are still various system blocks. For this purpose, the career of sports brokers must be normalized from the level of the state as soon as possible, and it is a problem to be urgently solved by authorities concerned that laws are formulated concerning the training and employment of the sports brokers, their rights and obligations, behavior norms.

\section{REFERENCES}

[1] A.N.Wise.Intenrational Sports Lawand Business [M].RlubmerIntenrational,1997.

[2] G.W.seully.The Mkaret Strueture of Sports[M].The Universiytof Chicagoofpress, 1996

[3] Xu Aili, Practice of Sports Brokers [D]. Fudan University,2013

[4] J.Quikr,RD.Fort.pay Dirt.The Business of porefssional Tema Sports[M].Prineeton Universiyt Press, 1992

[5] Ma Tie, Huang Wenhui, Zhang Li, Lin Xianpeng. Research into the Countermeasures for Development of Brokers in China [J].Sports Technology of China,2015,19(2) : 89-95

[6] B.Rubmghnad A.Braeke.The Europen Sport Club System.in Mastenalexis,CarolA.Barr,MaryA.Humz: Prinei Plesnad Praetiee of Sport Mnaagemeni [M].As Pen Publishers,Inc.1998

[7] Chen Li Nong. Preliminary Research into the Development Status of Sports Brokers and Countermeasures [J]. Journal of Guangzhou Sport Untversity,2014,39(2) : 18-21

[8] Ma Tie. Sports Brokers [M].Economic Press of China,2010

[9] Ou Yamin, Development Status of Sports Brokers and Countermeasures [J]. Group Economy, 2012,23(11)

[10] Xiong Doudou, Preliminary Research into the Status of China's Sports Brokers [J].Time Education: Education edition, 2014,36(10) : 123-126 